\title{
Cyberball: A Reasonable Paradigm for Research in Developmental Science?
}

\author{
Herbert Scheithauer ${ }^{\mathrm{a}, *}$, Françoise Alsaker ${ }^{\mathrm{b}}$, Ralf Wölfer ${ }^{\mathrm{c}}$ and Sabrina Ruggieri ${ }^{\mathrm{b}}$ \\ ${ }^{a}$ Department of Educational Science and Psychology, Freie Universität Berlin, Berlin, Germany \\ ${ }^{\mathrm{b}}$ Department of Psychology, University of Bern, Bern, Switzerland \\ ${ }^{\mathrm{c}}$ Department of Experimental Psychology, University of Oxford, Oxford, UK
}

Ostracism is defined as acts of ignorance or social exclusion by another individual or group (Williams, 2001), which can be described as a powerful negative experience that may have a negative impact on a child's socio-emotional development. When ostracized, people report feeling frustrated, anxious, or nervous (Williams, 2001). The initial reactions to ostracism are similarly felt by all individuals regardless of personality or social and situational factors. Ostracism then instigates actions aimed at recovering thwarted needs of belonging, self-esteem, control, and meaningful existence. Ostracism has been studied in many ways according to different traditions in various research areas (for excellent reviews see Williams, 2001; 2007). For example, some researchers have addressed it using methodologically sound survey scales with satisfying psychometric properties (Crick \& Grotpeter, 1996; Werner \& Crick, 2004) while others have addressed it in experimental studies utilizing rejection paradigms (Twenge, Catanese, \& Baumeister 2003; Zadro, Williams, \& Richardson, 2004). In this respect, the most commonly applied assessment form has been the cyberball paradigm (Williams, Cheung, \& Choi, 2000).

\footnotetext{
*Address for correspondence

Prof. Dr. Herbert Scheithauer, Freie Universität Berlin, Department of Educational Science and Psychology, Habelschwerdter Allee 45, 14195 Berlin, Germany. E-mail: hscheit@zedat.fu-berlin.de.
}

\section{Measurement Issues: Experimental Manipulation of Ostracism}

Cyberball is an experimental paradigm, an ostensibly online ball-tossing game, in which participants believe they are playing with two or three other persons. As can be seen in Fig. 1, this virtual ball-tossing game involves three players: one participant as well as two confederates, who are described as real in the introductory cover story but constitute, in fact, standardized computer players. While participants in the control group get the ball as often as the other players, participants in the experimental group become ostracized by the two confederates after a short while.

This elegant paradigm allows researchers to experimentally initiate ostracism in a very economical way, because cyberball is implemented comfortably on the computer, either in a laboratory or via the internet, and the negative ostracism experience lasts for only two minutes. Moreover, this software easily allows developing program modifications in order to examine ostracism effects within slightly changed cyberball environments (e.g. Van Beest \& Williams, 2006; Wölfer $\&$ Scheithauer, 2012), which is of vital importance for experimental science. Finally and most important, compelling evidence supports the validity of cyberball, which expectedly causes negative affects, threatens basic psychological needs, and triggers antisocial or maladaptive reactions (for an overview see Williams, 2007). 


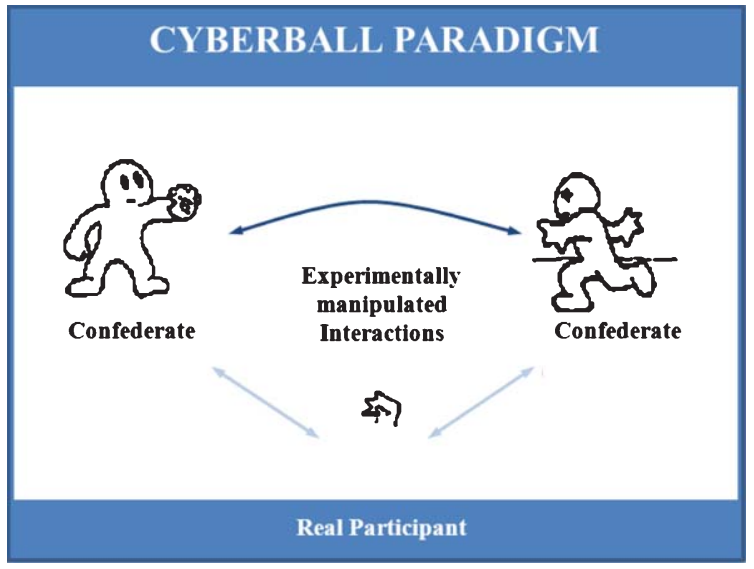

Figure 1. Cyberball paradigm ${ }^{1}$ : Screenshot from online ball-tossing game. Note: Text and arrows are shown for descriptive reasons and are not presented within the experiment.

\section{Use of the Cyberball Paradigm in Empirical Research}

Consequentially, cyberball was applied in more than 100 studies, which primarily cover the research fields of social psychology (e.g. Bernstein, Sacco, Young, Hugenberg, \& Cook, 2010), clinical psychology (e.g. Lawrence, Chanen, \& Allen, 2011), and biological psychology (e.g. Geniole, Carréa, \& McCormicka, 2011). However, even though ostracism happens across the entire life span as a ubiquitous part of our interpersonal behavior (Williams, 2001), researchers started only recently to focus on child and adolescent samples for examining developmental aspects of ostracism. Thus, although the cyberball paradigm has often been used in studies and the impact of social ostracism within the cyberball paradigm has often frequently been investigated in research, little is known with regard to its significance for a developmental perspective. Many experimental studies have been carried out on adult populations reporting levels of distress after brief periods of ostracism. There is some evidence that individuals' sensitivity to exclusion is particularly high in adolescents as compared to younger children or adults (Masten et al., 2009; Pharo, Gross, Richardson, \& Hayne, 2011; Sebastian, Viding, Williams, \& Blakemore, 2010) due to the increased importance placed on maintaining peer relationships in this period of life (i.e. Larson \& Richards, 1991). Therefore, in depth investigations of ostracism in a developmental frame are of great

\footnotetext{
${ }^{1}$ See http://www1.psych.purdue.edu/ willia55/Announce/ cyberball.htm
}

importance, including studies with age groups covering the entire life span. A literature overview of all studies in which the paradigm has been used in younger samples is presented in Table 1.

A closer look at the results of the studies listed in Table 1 reveals that sex effects in response to ostracism seem to be rather small. With regard to need threats strong negative responses to ostracism are usually found across all age categories, but they are more or less pronounced depending on the needs and the age groups. In addition, possible moderator variables have been investigated. For example, some researchers have examined whether children with autism spectrum disorders react differently to ostracism (Bolling et al., 2011b; Masten et al., 2011; Sebastian, Blakemore, \& Charman, 2009; Zadro, Boland, \& Richardson, 2006) or how social anxiety moderates responses to ostracism. However it has rarely been examined whether certain subgroups of children and adolescents (e.g. with internalising problems, depression, social anxiety, or with victimization/bullying experiences) respond differently to ostracism episodes in experimental studies - and whether such differential reactions may have important implications for research on (mal)adaptive psychosocial child and adolescent development. Another prominent area of research involves neural correlates of ostracism. Social exclusion has been shown to activate the same brain regions that are activated in physical pain. Moreover, the brain regions associated with social pain seem to be the same in adults (Eisenberger, Lieberman, \& Williams, 2003) and in early adolescents (Bolling et al. 2011a).

Although some studies in the field of ostracism consider a developmental perspective (e.g., examination of biopsychosocial factors, comparison of normal with psychopathological development etc.; c.f. Scheithauer, Niebank, \& Gottlieb, 2007), there is a lack of longitudinal studies investigating the impact of ostracism, the developmental function, and developmental antecedents such as individual differences in the perception of ostracism. All but one study listed in Table 1 are cross-sectional and investigate ostracism by contrasting specific age groups, while only two studies investigate the impact of ostracism in older age groups. Therefore, there is a clear need to examine ostracism and its impact from a life span perspective.

\section{Scope of the Thematic Issue}

This thematic issue of the International Journal of Developmental Science (IJDS) focuses on studies 
Table 1

Selection of Studies with Child and/or Adolescent Samples Using the Cyberball Paradigm and Selected Key Findings

\begin{tabular}{lll}
\hline Authors & Participants N (Mean Age) & Key Findings \\
\hline Abrams et al. (2011) & 41 (Age: 8-9 year olds) & Ostracism threatened four primary needs and mood. Self-esteem \\
& 79 (Age: 13-14 year olds) & was more threatened among 8- to 9-year olds than among older \\
& 46 (Age: 20 -year olds) & participants. Among 13- to14- year olds belonging was \\
& particularly threatened.
\end{tabular}

Bolling et al. (2011a) 26 (Age: 7-17 year olds)

Age related changes in the neural correlates of social exclusion across the transition from middle childhood to adolescence were found.

Bolling et al. (2011b) 24 typically developing $(M=12.83)$ 24 Autism Spectrum Disorders (ASD) $(M=12.81)$

Coyne et al. (2011)

40 (Age: 16-17 year olds)

Crowley et al. (2010)

$33(M=10.76 ; S D=1.32)$

Gross (2009)

Masten et al. (2011)

Moor et al. (2012)

Pharo et al. (2011)

Ruggieri et al. (2013a)

Salvy et al. (2012)

$103(M=13.6)$

Sebastian et al. (2009)

13 Autism Spectrum Disorders $(M=16.9)$ 16 typically developing $(M=16.9)$

Sebastian et al. (2010)

$26(M=12.8)$

$25(M=15.0)$

$26(M=27.4)$

Wölfer \& Scheithauer (2012) $53(M=10.0, S D=0.6)$

$40(M=14.4, S D=0.5)$
Though both groups of children reported equal distress following exclusion, the results demonstrate neurobiological differences in processing social exclusion in children with ASD.

Participants' levels of pronounced prosocial behavior was measured after playing cyberball, and personality traits were examined as possible moderators in participant behavioral responses. Results revealed that, compared to controls, ostracized adolescents showed less prosocial behavior, and this was moderated by having an "open" personality.

Distress from an exclusion episode was associated with greater slow wave neural activity in cortical regions.

Excluded participants reported a lowered state of self-esteem and relational value as well as higher levels of dysphoria, shame, and anger. These effects were independent of sex and age.

Compared to typically developing adolescents, those with ASD displayed less activity in regions previously linked with the distressing aspect of peer exclusion, as well as less activity in regions previously linked with the regulation of distress responses during peer exclusion. However, both groups self-reported equivalent levels of distress after the experience of ostracism.

Social exclusion generated strong distress for all age groups, but 10-12 year olds showed increased activity in the subgenual ACC in the exclusion game.

Ostracism negatively affected participants' basic needs, but the magnitude of the effect was larger in the two younger age groups.

Adolescents in the ostracism condition reported lower levels of needs and mood compared to non ostracized students.

Ostracized adolescents were more motivated to earn food in a task than adolescents who were in the included/control condition. Results suggest that social connection-related activities following ostracism may further deplete self-regulatory resources, thereby resulting in increased unhealthy food patterns.

Anxiety and the four needs (belonging, self-esteem, meaningful existence, and control) were negatively affected by ostracism in both groups. However, ostracism did not modulate mood in the ASC group.

Main effects of being ostracized for all four needs with lower need fulfilment following ostracism and a main effect of age for self-esteem (mid-adolescents were significantly lower than adults). Mood was significantly less positive after ostracism in both young-adolescents and mid-adolescents but not in adults.

Ostracism caused negative emotions and selective memory for social events for both children and adolescents. The results confirm the usefulness of cyberball beyond self-reports. 
utilizing the experimental cyberball paradigm (cf. Williams et al., 2000) with a "developmental science" focus on ostracism. With this thematic issue, we aim to promote this promising trend and seek to address some of the yet open developmental research questions within the field of ostracism. In particular, built on the recent and fruitful insights summarized in Table 1, more research is needed to uncover developmental mechanisms across the entire life span (e.g. phylogenetic and ontogenetic function of ostracism), to examine longitudinal effects of ostracism (e.g. as a social regulator mechanism vs. risk factor for psychopathology), as well as to validate and adjust cyberball to specific age groups (e.g. cognitive and social prerequisites to participate in the experimental ostracism paradigm).

Following a call for papers resulting in the submission of numerous abstracts we invited renowned researchers from the field of ostracism research to submit studies from their labs using the cyberball paradigm. Following a regular peer review process we finally included six manuscripts in the thematic issue and invited Kipling D. Williams and Eric D. Wesselmann to write a commentary on the submitted manuscripts, the whole thematic issue respectively (2013). We are very pleased that both colleagues accepted our invitation.

All of the studies described in the six manuscripts used the cyberball paradigm - or adaptations of the paradigm - to investigate processes of ostracism and all of the studies consider very different perspectives to enrich the research field with a perspective from developmental science and clinical psychology. Zadro and colleagues (2013) provide us - on the background of their own empirical experience - with important guidelines, which target the suitability of the cyberball paradigm in studies with children (e.g. including age-dependent modifications of the paradigm). Additionally, they discuss a post-cyberball assessment of primary need-threat that is appropriate for use with a child sample. Four studies deal with the consequences of ostracism and factors influencing the impact of ostracism experiences. Guroglu, Will, and Klapwijk (2013) use an innovative experimental design to examine how real-life peer relationships modulate altruistic punishment (in the form of economic exchange games where they could invest money to increase or decrease the payoffs of the players from the preceding cyberball session) of bullies and compensation of victims after observed ostracism in young adulthood. Their study gives important insight into the impact of observing ostracism and associated retaliation or compensation processes depending on the relationship with the bully and the victim. Ruggieri, Bendixen, Gabriel, and Alsaker (2013b) investigated whether victims of bullying show more pronounced responses to single episodes of social exclusion in a sample of early adolescents. Their results "support the idea that previously victimized students are more affected by experiences of social exclusion than students who are not involved in bully/victim problems." (p. 25). Wesselmann, Ren, Swim, and Williams (2013) examine whether rumination - as a negative style of cognitive appraisal hinders individuals' ability to recover from ostracism experiences in a laboratory experiment. They found that participants who were allowed to ruminate after induced ostracism reported more distress than ostracized participants who were distracted, suggesting less recovery upon rumination. Their findings have important implications especially for chronically ostracized individuals. Hawes and colleagues (2013) examine associations between ostracism, internalising problems, and threat to the primary needs "belonging", "control", "self-esteem", and "meaningful existence" in children. They found that internalizing problems influence the relationship between ostracism experiences and threat to primary needs but interestingly not in the hypothesized direction. That is: "Internalising problems were associated with a threat to belonging, but only in the social inclusion condition." (p. 43). Their findings "suggest that ostracism is so aversive that the presence of internalising problems may not aggravate threatened feelings of belongingness over and above the act of being excluded and ignored." (p. 43). Finally, Celik, van Beest, Lammers, and Bekker (2013) report findings from their study with individuals from a special population, that is male violent offenders diagnosed with Antisocial Personality Disorder (ASPD) compared with individuals without diagnosed ASPD. In their study, participants played an altered version of the cyberball game in which they could control the course of the game or not. Their findings have important implications for the etiology of ASPD.

This thematic issue contributes to the growing research on ostracism and its impact on child's and adolescent's development. However, we are only at the beginning because longitudinal studies with a developmental background are still lacking. Our hope is that this thematic issue might contribute to this important and thrilling research field. We want to thank the authors of the manuscripts for their contribution to this thematic issue. Finally, we want to thank all those who responded to our call for abstracts, although in the end not all proposals could be included. 


\section{Conclusions}

Despite the positive trend within the last two years, ostracism using the cyberball paradigm is yet an underrepresented area of research with respect to a developmental science perspective. It is important to study ostracism and its impact using comparable experimental methodologies across studies and across the life-span in order to examine age-specific effects, to capture the longitudinal impact, and to disentangle developmental processes of this omnipresent interpersonal behavior. In this respect, we are confident that cyberball presents a valuable tool to challenge these research questions which can be judged as an adequate paradigm for research with children and adolescents. In the history of psychology, experiments were found to advance developmental science (e.g. Ainsworth, Blehar, Waters, \& Wall, 1978; Bandura, 1965; Mischel, Shoda, \& Rodriguez, 1989); similarly, the experimental cyberball paradigm promises a research avenue which furthers our understanding concerning the antecedents, consequences, and their corresponding developmental mechanisms of ostracism.

\section{References}

Abrams, D., Weick, M., Thomas, D., Colbe, H., \& Franklin, K. M. (2011). On-line ostracism affects children differently from adolescents and adults. British Journal of Developmental Psychology, 29, 110-123.

Ainsworth, M. D. S., Blehar, M. C., Waters, E., \& Wall, S. (1978). Patterns of attachment: A psychological study of the Strange Situation. Hillsdale, NJ: Erlbaum.

Bandura, A. (1965). Influence of models reinforcement contingencies on the acquisition of imitative response. Journal of Personality and Social Psychology, 1, 589-595.

Bernstein, M. J., Sacco, D. F., Young, S. G., Hugenberg, K., \& Cook, E. (2010). Being "in" with the in-crowd: The effects of social exclusion and inclusion are enhanced by the perceived essentialism of ingroups and outgroups. Personality and Social Psychology Bulletin, 36, 999-1009.

Bolling, D., Pitskel, N. B., Deen, B., Crowley, M. J., Mayes, L. C., \& Pelphrey, K. A. (2011a). Development of neural systems for processing social exclusion from childhood to adolescence. Developmental Science, 14, 1431-1444.

Bolling, D., Pitskel, N. B., Deen, B., Crowley, M., McPartland, J. C., Kaiser, M. D., Wyk, B.C., Wu, J., Mayes, L.C., \& Pelphrey, K. A. (2011b). Enhanced neural responses to rule violation in children with autism: A comparison to social exclusion. Developmental Cognitive Neuroscience, 1, 280-294.

Çelik, P., van Beest, I., Lammers, J., \& Bekker, M. (2013). Implicit threat vigilance among individuals diagnosed with Antisocial Personality Disorder (ASPD): The impact of ostracism and control threat. International Journal of Developmental Science, 7, 47-55.
Crick, N. R., \& Grotpeter, J. K. (1996). Children's treatment by peers: Victims of relational aggression and overt aggression. Development and Psychopathology, 8, 367-380.

Geniole, S. N., Carréa, J. M., \& McCormicka, C. M. (2011). State, not trait, neuroendocrine function predicts costly reactive aggression in men after social exclusion and inclusion. Biological Psychology, 87, 137-145.

Coyne, S. M., Gundersen, N., Nelson, D. A., \& Stockdale, L. (2011). Adolescents prosocial responses to ostracism: An experimental study. The Journal of Social Psychology, 151, 657-661.

Crowley, M. J., Wu, J., Molfese, P. J., \& Mayes, L. C. (2010). Social exclusion in middle childhood: Rejection events, slowwave neural activity, and ostracism distress. Social Neuroscience, 5, 483-495.

Eisenberger, N. I., Lieberman, M. D., \& Williams, K. D. (2003). Does rejection hurt? An fMRI study of social exclusion. Science, 302, 290-292.

Gross, E. F. (2009). Logging on, bouncing back: An experimental investigation of online communication following social exclusion. Developmental Psychology, 45, 1787-1794.

Güroğlu, B., Will, G.-J., \& Klapwijk, E. (2013). Some bullies are more equal than others: Peer relationships modulate altruistic punishment of bullies after observing ostracism. International Journal of Developmental Science, 7, 13-23.

Hawes, D. J., Zadro, L., Iannuzzelli, R., Godwin, A., MacNevin, G., Dadds, M.R., Griffiths, B., \& Richardson, R. (2013). Internalising problems and the effects of peer ostracism on children's primary needs. International Journal of Developmental Science, 7, 41-45.

Kloep, M. (1999). Love is all you need? Focusing on adolescents life concerns from an ecological point of view. Journal of Adolescence, 22, 49-63.

Larson, R. W., \& Richards, M. H. (1991). Daily companionship in late childhood and early adolescence: Changing developmental contexts. Child Development, 62, 284-300.

Lawrence, K. A., Chanen, A. M., \& Allen, J. S. (2011). The effect of ostracism upon mood in youth with borderline personality disorder. Journal of Personality Disorders, 25, $702-714$.

Masten, C., Eisenberger, N., Borofsky, L., Pfeiffer, J., McNealy, K., Mazziotta, J., \& Dapretto, M. (2009). Neural correlates of social exclusion during adolescence: The distress of peer rejection. Social Cognitive and Addictive Neuroscience, 4, 143-157.

Masten, C. L., Colich, N. L., Rudie, J. D., Bookheimer, S. Y., Eisenberger, N. I., \& Dapretto, M. (2011). An fMRI investigation of responses to peer rejection in adolescents with autism spectrum disorders. Developmental Cognitive Neuroscience, 1, 260-270.

Mischel, W., Shoda, Y., \& Rodriguez, M. L. (1989). Delay of gratification in children. Science, 244, 933-938.

Moor, B., Guroglu, B., Op de Macks, Z., Rombouts, S., Van der Moulen, M., \& Crone, E. (2012). Social exclusion and punishment of excluders: Neural correlates and developmental trajectories. Neurolmage, 59, 708-717.

Pharo, H., Gross, J., Richardson, R., \& Hayne, H. (2011). Age-related changes in the effect of ostracism. Social Influence, 6, 22-38.

Ruggieri, S., Bendixen, M., Gabriel, U., \& Alsaker, F. (2013a). Cyberball: The impact of ostracism on the well-being of early adolescents. Swiss Journal of Psychology, 72, 103-109.

Ruggieri, S., Bendixen, M., Gabriel, U., \& Alsaker, F. (2013b). Do victimization experiences accentuate reactions to ostracism? An experiment using cyberball. International Journal of Developmental Science, 7, 25-32. 
Scheithauer, H., Niebank, K., \& Gottlieb, G. (2007). To see an elephant: Developmental Science. European Journal of Developmental Science, 1, 6-22.

Salvy, S., Bowker, J. C., Nitecki, L., Kluczynski, M. A., Germeroth, L. J., \& Roemmich, J. N. (2012). Effects of ostracism and social connection-related activities on adolescents motivation to eat and energy intake. Journal of Pediatric Psychology, 37, 23-32.

Sebastian, C., Blakemore, S., \& Charman, T. (2009). Reactions to ostracism with autism spectrum conditions. Journal of Autism and Developmental Disorders, 39, 1122-1130.

Sebastian, C., Viding, E., Williams, K., \& Blakemore, S. (2010). Social brain development and the affective consequences of ostracism in adolescence. Brain and Cognition, 72, 134-145.

Twenge, J., Catanese, K., \& Baumeister, R. (2003). Social exclusion and the deconstructed state: Time perception, meaninglessness, lethargy, lack of emotion, and self-awareness. Journal of Personality and Social Psychology, 85, 409-423.

Van Beest, I., \& Williams, K. D. (2006). When inclusion costs and ostracism pays, ostracism still hurts. Journal of Personality and Social Psychology, 91, 918-928.

Werner, N. E., \& Crick, N. R. (2004). Maladaptive peer relationships and the development of relational and physical aggression during middle childhood. Social Development, 13, 495-514.

Wesselmann, E. D., Ren, D., Swim, E., \& Williams, K. D. (2013). Rumination hinders recovery from ostracism. International Journal of Developmental Science, 7, 33-39.

Williams, K. D. (2001). Ostracism: The power of silence. New York: Guilford.

Williams, K. D. (2007). Ostracism. Annual Review of Psychology, $58,425-452$.

Williams, K. D., Cheung, C., \& Choi, W. (2000). Cyberostracism: Effects of being ignored over the Internet. Journal of Personality and Social Psychology, 79, 748-762.

Wesselmann, E., \& Williams, K. D. (2013). A Commentary on "Cyberball: A Reasonable Paradigm for Studying Ostracism in Developmental Science?".
Wölfer, R., \& Scheithauer, H. (2012). Ostracism in childhood and adolescence: Emotional, cognitive, and behavioral effects of social exclusion. Social Influence, 1-20 (i-first) DOI: 10.1080/15534510.2012.706233

Zadro, L., Boland, C., \& Richardson, R. (2006). How long does it last? Persistence of the effects of ostracism in the socially anxious. Journal of Experimental Social Psychology, 42, 692-697.

Zadro, L., Hawes, D. J., Iannuzzelli, R., Godwin, A., MacNevin, G., Griffiths, B., \& Gonsalkorale, K. (2013). Ostracism and children: A guide to effectively using the cyberball paradigm with a child sample. International Journal of Developmental Science, 7, 7-11.

Zadro, L., Williams, K. D., \& Richardson, R. (2004). How low can you go? Ostracism by a computer is sufficient to lower self-reported levels of belonging, control, self-esteem, and meaningful existence. Journal of Experimental Social Psychology, 40, 560-567.

\section{Bio Sketches}

Herbert Scheithauer is Professor for Developmental and Clinical Psychology at Freie Universität Berlin and Head of the Unit "Developmental Science and Applied Developmental Psychology".

Françoise D. Alsaker is a Professor for Developmental Psychology at the University of Bern, Switzerland. In the last decade, her research has focused on victimization and its prevention through kindergarten and primary school.

Ralf Wölfer received his doctoral degree from Freie Universität Berlin, Germany, Department of Educational Science and Psychology. Currently, he is working as a research scientist at the University of Oxford (Department of Experimental Psychology).

Sabrina Ruggieri is a PhD Student in Developmental Psychology at the University of Berne. Her research interests include victimization, peer exclusion, and peer relationships in childhood and adolescence. 